\title{
PARADIGMA DA COMPLEXIDADE E LINGUÍSTICA APLICADA: RELAÇÕES E PROPRIEDADES A PARTIR DE PRODUÇÕES CINEMATOGRÁFICAS
}

\author{
COMPLEXITY PARADIGM AND APPLIED LINGUISTCS: RELATIONSHIPS AND \\ PROPERTIES FROM FILM PRODUCTIONS
}

\author{
Gisele da Cruz Rosa \\ Universidade Federal de Uberlândia \\ Valeska Virgínia Soares Souza Correio \\ Instituto Federal do Triângulo Mineiro
}

O caos é uma ordem por decifrar (...) os algarismos não têm sentido fora de uma qualquer ordem que se lhes dê, o problema está em saber encontrá-la (SARAMAGO, 2008, p. 90).

\begin{abstract}
RESUMO: Este artigo visa apresentar as propriedades dos sistemas complexos, a saber: dinamicidade, conectividade, não-linearidade, emergência, imprevisibilidade, sensibilidade às condições iniciais, auto-organização, sensibilidade à feedback, bifurcação, adaptabilidade, caos e abertura, a partir de produções cinematográficas e de narrativas acerca das experiências de aprendizagem de inglês e do uso de ferramentas tecnológicas produzidas por estudantes do Programa Idiomas sem Fronteiras - inglês. A fundamentação teórica reside no Paradigma da Complexidade e o percurso metodológico constitui-se qualitativo. As análises demonstram que todas as propriedades apresentadas podem ser percebidas tanto nos filmes, como nas narrativas, podendo ser consideradas imbricadas nos exemplos do mundo fenomênico que vivemos.
\end{abstract}

PALAVRAS-CHAVE: Complexidade; Produções cinematográficas; Linguística Aplicada.

ABSTRACT: This paper presents the properties of complex systems, namely: dynamism, connectivity, nonlinearity, emergence, unpredictability, sensitivity to initial conditions, selforganization, sensitivity to feedback, bifurcation, adaptability, chaos and openness, from movie productions and from narratives about the experiences of learning English and the use of technological tools produced by learners from the program Languages without Borders - English. The theoretical basis lies on the Paradigm of Complexity and the methodological approach constitutes as a qualitative research. The analysis shows that all the properties presented can be seen both in the films and in the narratives, and should be considered imbricated in the examples of the phenomenal world we live in.

KEYWORDS: Complexity; Film productions; Applied Linguistics.

\section{INTRODUÇÃO}

Neste artigo, pretendemos demonstrar o quão complexos são os fenômenos estudados na Linguística Aplicada. Por complexos, não queremos dizer complicados, mas 


\section{Revista do SELL}

v. 5 , no. 1

ISSN: 1983-3873

aqueles que abrangem interconexão e dinamicidade, quando observados através das lentes do Paradigma da Complexidade.

O Paradigma da Complexidade preocupa-se com o comportamento dos sistemas dinâmicos, ou seja, aqueles que mudam com o tempo, e propõe uma visão holística desses sistemas. Os sistemas dinâmicos ou complexos são auto-organizáveis e adaptativos, pois buscam aproveitar tudo o que acontece, e não apenas reagir passivamente; consequentemente, nesses sistemas, aprende-se com as experiências vividas (WALDROP, 1992).

Sistemas complexos e Linguística Aplicada têm gradualmente sido vistos juntos em publicações desde o artigo seminal de Larsen-Freeman (1997). Referências de outras áreas do conhecimento também podem ilustrar a complexidade inerente a muitos sistemas, por isso buscamos nas produções cinematográficas: A Viagem (original Cloud Atlas), Babel (original Babel), O curioso caso de Benjamin Button (original The Curious Case of Benjamin Button), Corra Lola Corra (original Lola rennt), Efeito Borboleta (original The ButterflyEffect), e A Teoria do Caos (original Chaos Theory) subsídios iniciais para nossas considerações acerca das propriedades dos sistemas complexos. Essas propriedades (dinamicidade, conectividade, não-linearidade, emergência, imprevisibilidade, sensibilidade às condições iniciais, auto-organização, sensibilidade à feedback, bifurcação, adaptabilidade, caos e abertura) são exemplificadas a partir dessas produções.

Os sistemas adaptativos complexos mudam com o tempo, e não há como determinar, exatamente, como tais mudanças acontecerão. Essas mudanças são influenciadas não apenas pelas condições iniciais em que eles surgem, mas também porque os sistemas adaptativos complexos se adaptam, à medida que recebem feedback. Como esses sistemas são abertos a novas matérias e energias, ao passo que evoluem, a absorção de energia do ambiente aumenta sua ordem e sua complexidade. As mudanças que acontecem, natural e automaticamente, nos sistemas podem ser definidas pelo processo de auto-organização.

Os elementos reorganizam-se entre si e com suas interfaces, para atingirem melhor os objetivos do sistema. Essa complexidade pode ser também observada no processo de ensino e aprendizagem de língua, fenômeno de interesse de linguistas aplicados. Vetromille-Castro e Duarte (2011) consideram qualquer grupo em situação de aprendizagem como um sistema complexo. Vetromille-Castro (2011) compreende a sala 


\section{Revista do SELL}

v. 5 , no. 1

ISSN: 1983-3873

de aula como um grupo social, isto é, um espaço interativo propício para a construção do conhecimento por meio de eventos com momentos estáveis e instáveis diretamente ligados ao ambiente que os rodeiam e que interferem em seu curso constantemente. Estas influências resultantes da emergência dos comportamentos são decisivas na constituição e na manutenção dos sistemas. Os elementos do sistema, sensíveis ao feedback, interagem entre si e se adaptam aos outros e ao contexto. A sala de aula como um sistema adaptativo complexo abrange agentes (por exemplo, os aprendizes) e elementos que compõem um sistema que se auto-organiza para se adaptar a novos padrões e comportamentos. O aprendiz de línguas também é visto como um sistema complexo devido à sua personalidade individual, que está dentro da sala de aula, que é outro sistema, que está dentro da instituição de ensino, que também é sistema, que está dentro do sistema nacional de educação (FINCH, 2002).

Considerando o exposto, a demonstração da complexidade dos fenômenos estudados na Linguística Aplicada se dará pela comparação e reflexão dos dados da revisão bibliográfica, amparada por ilustrações extraídas das referidas reproduções cinematográficas e por autobiografias de aprendizes de língua inglesa que narram suas experiências de aprendizagem e do uso de ferramentas tecnológicas neste processo.

Além desta introdução, nosso texto está organizado em nove outras seções, sendo a primeira apresentando a fundamentação teórica da pesquisa e a segunda o percurso metodológico. Posteriormente, expomos a seis seções de análise, tanto relacionadas aos filmes como às narrativas dos aprendizes. Encerramos com algumas considerações, seguidas das referências.

\section{PARADIGMA DA COMPLEXIDADE E LINGUÍSTICA APLICADA}

A Complexidade, segundo Morin,

[é] um tecido (complexus: o que é tecido junto) de constituintes heterogêneas inseparavelmente associadas: ela [a complexidade] coloca o paradoxo do uno e do múltiplo. Num segundo momento, a complexidade é efetivamente o tecido de acontecimentos, ações, interações, retroações, determinações, acasos, que constituem nosso mundo fenomênico" (MORIN, 2006, p. 13).

O Paradigma da Complexidade propõe um percurso investigativo do comportamento dos sistemas dinâmicos. Sistema é o resultado de um conjunto de componentes que interagem entre si visando alcançar um estado geral ou uma unidade 


\title{
Revista do SELL
}

v. 5 , no. 1

ISSN: 1983-3873

(LARSEN-FREEMAN; CAMERON, 2012). Os sistemas dinâmicos ou complexos são autoorganizáveis e adaptativos, pois buscam aproveitar tudo o que acontece, e não apenas reagir passivamente; portanto, nesses sistemas, aprende-se com as experiências vivenciadas (WALDROP, 1992).

Um sistema complexo, de acordo com Paiva (2006, p. 91)

não é um estado, mas um processo. Cada componente do sistema pertence a um ambiente construído pela interação entre suas partes. Nada é fixo, ao contrário, existe um constante movimento de ação e reação e mudanças acontecem com o passar do tempo.

Neste sentido, um sistema complexo apresenta diversos tipos de elementos, geralmente em grande quantidade, que se conectam e interagem e, consequentemente, modificam suas formas. Esta dinamicidade, que resulta em mudanças, é o ponto central do Paradigma da Complexidade. Segundo Larsen-Freeman e Cameron (2012)

\begin{abstract}
Em função de sua não-linearidade, sistemas complexos se desenvolvem e se adaptam de diferentes modos, internamente e através de conexões externas ao seu ambiente. Mudanças na auto-organização interna alteram a estrutura do sistema; enquanto repostas a energia e matéria externas, leva a mudança adaptativa mantendo a ordem e a estabilidade ${ }^{1}$ (LARSEN-FREEMAN; CAMERON, 2012, p. 43, 44).
\end{abstract}

Davis e Sumara (2006, p. 127) entendem o pensamento complexo como uma noção de guarda-chuva que "permite que os pesquisadores notem similaridades profundas entre uma diversidade de fenômenos". Teorias relacionadas ao Paradigma da Complexidade foram, inicialmente relacionadas à Física e à Matemática. A área da Educação, inclusive a de Linguística Aplicada (LA), passou a utilizar, nas últimas décadas, essa nova alternativa para a condução de suas pesquisas, uma abordagem nãoreducionista e não-linear, embasada no pensamento complexo (DAVIS; SUMARA, 2006). As propriedades que nos interessam nessa pesquisa são provenientes da Teoria Geral dos Sistemas, da Teoria do Caos e da Teoria dos Sistemas Complexos.

O interesse de teóricos da LA pelo Paradigma da Complexidade provém não apenas de pesquisadores ansiosos para se esquivar das dicotômicas pesquisas tradicionais sobre língua adicional (KRAMSCH, 2012), mas também de pesquisadores

1 Essa e demais traducões são de nossa responsabilidade. 


\section{Revista do SELL}

v. 5 , no. 1

ISSN: 1983-3873

conceituados como Larsen-Freeman (2012) que tem relacionado pressupostos desse paradigma com a aquisição de língua estrangeira desde a publicação de seu artigo seminal, no qual a autora relaciona os sistemas complexos encontrados na natureza e a aprendizagem de segunda língua (LARSEN-FREEMAN, 1997).

A aprendizagem de línguas é um processo complexo e influenciável por diversos fatores; os quais não podem ser considerados lineares e serem reduzidos a uma causa e um efeito. Isto significa que estes fatores não adotam uma relação proporcional na qual é possível prever quando um comportamento aleatório vai ocorrer. Os sistemas complexos são formados por múltiplos componentes ou agentes, de igual modo, aprender uma língua abrange diversos agentes e elementos que interagem entre si (contexto, ambiente, método, aprendiz, professor, entre outros) se adaptando a cada caso e especificidade do ambiente de ensino, não podendo os resultados ser alcançados por meio de uma fórmula fixa de causa e efeito (VAN LIER, 2004).

Os múltiplos fatores envolvidos, e que interagem entre si, no processo complexo de aquisição de segunda língua, determinam o grau de sucesso no processo de aprendizagem. Os sistemas interagentes apresentam (em diferentes graus) as seguintes propriedades: dinamicidade, conectividade, não-linearidade, emergência, imprevisibilidade, sensibilidade às condições iniciais, auto-organização, sensibilidade à feedback, bifurcação, adaptabilidade, caos e abertura, discutidas detalhadamente, posteriormente, a partir de produções cinematográficas e de narrativas de aprendizes de língua inglesa.

\section{PERCURSO METODOLÓGICO}

A primeira fase dessa pesquisa foi buscar produções cinematográficas que retratassem a complexidade de nosso mundo fenomênico. Seis filmes foram selecionados - A Viagem, Babel, O curioso caso de Benjamin Button, Corra Lola Corra, Efeito Borboleta, e A Teoria do Caos - assistidos e analisados. Buscamos as propriedades do paradigma da complexidade mais marcantes em cada um, mesmo cientes de que todas as propriedades estavam presentes em todos eles. 


\section{Revista do SELL \\ v. 5 , no. 1 \\ ISSN: $1983-3873$}

Este artigo tem como corpus, além das produções cinematográficas, excertos de autobiografias coletadas para a dissertação de Rosa ${ }^{2}$ (2015). As narrativas foram coletadas em cursos de língua inglesa do Programa Idiomas Sem Fronteiras (doravante ISF) da Universidade Federal de Uberlândia. Os objetivos do IsF são: 1) contribuir com a formação em língua inglesa de possíveis candidatos ao Programa Ciência sem Fronteiras (CsF); 2) preparar seus alunos para exames de língua inglesa solicitados para admissão em instituições acadêmicas no exterior.

Os dados do corpus foram coletados utilizando a abordagem autobiográfica visando a produção de estudos de caso sobre experiências individuais dos alunos. Tratase de histórias individuais em que os aprendizes narram suas experiências (BENSON; NUNAN, 2005).

Estudos realizados no campo da LA na área do ensino de línguas (PAIVA, 2006; MORIN, 2006; SOUZA, 2011; ROSA, 2015) têm percebido o aprendiz como complexo e seu processo de aprendizagem de língua adicional é movido, principalmente, pelas propriedades de diversidade e dinamicidade. Tendo em vista a definição de autobiografia que orienta este estudo, buscamos nos relatos dos aprendizes dados que abrangessem suas trajetórias de estudo de língua inglesa e o papel das tecnologias digitais no processo de aprendizagem do idioma.

Foram feitas várias leituras das narrativas com o objetivo de selecionar excertos que nos ajudariam a compreender o que as experiências relatadas pelos aprendizes revelam sobre as propriedades do Paradigma da Complexidade. Nas seções que se seguem, apresentamos as análises dos filmes e das narrativas.

\section{DINAMICIDADE E CONECTIVIDADE A PARTIR DE "A VIAGEM"}

Sistemas dinâmicos diferenciam-se dos estáticos, pois têm como característica marcante a mudança. Mesmo marcados por alterações, os sistemas dinâmicos que compõem nosso mundo fenomênico não estão separados uns dos outros, pelo contrário, estão conectados formando um todo de partes que se interrelacionam. Lewin (1992) ilustra sistemas dinâmicos e conectados a partir da seguinte cena: alguém navegando em um mar agitado e perigoso no meio de rochas e enseadas quando se iniciam redemoinhos, devido à topografia do solo oceânico e ao fluxo de água. Um dos vórtices o

2 Dissertação defendida em dezembro de 2015, posteriormente à redação deste artigo. 


\section{Revista do SELL}

v. 5 , no. 1

ISSN: 1983-3873

arrasta até que uma mudança no fluxo o expulsa para outro vórtice. As mudanças acontecem porque todos os elementos (solo, água, rochas, vento) e o agente (o navegador) estão conectados. As duas propriedades, dinamicidade e conectividade, podem também ser observadas no filme " $A$ Viagem".

"A Viagem" explora como as ações e consequências de vidas individuais impactam nas vidas uns dos outros e no ambiente que os circunda, sociohistoricamente. Cada membro da trama aparece em múltiplos papeis enquanto o enredo progride no tempo. A história começa com o diário de um dono de escravos em potencial que viaja pelo Pacífico em 1849; depois um compositor talentoso escreve cartas para seu amante na Inglaterra dos anos de 1930; seguido por uma repórter que investiga um caso corrupto sobre uma usina nuclear estadounidense na década de 1970; sucedido pelo encarceramento de um editor em um asilo em 2012; na sequência, acontece uma emocionante rebelião de clones na Coréia em 2144; e finalmente, o membro de uma tribo luta com canibais no Havaí em uma era pós-apocalíptica depois de 2300. Essas seis histórias são apresentadas paulatinamente em idas e vindas no decorrer do filme. Cada uma mostra o enfrentamento das normas corruptas do seu tempo, mudando o curso da história, e moldando o futuro por meio de atos de bondade, menos e mais significativos.

É interessante observar que as seis histórias são marcadas por mudanças que impactam diacronicamente e sincronicamente o enredo. Somni451, por exemplo, a garçonete que era um clone humano, se manifesta contra a escravidão e assassinato em série e é executada. Essa execução impacta em seu tempo, propiciando mudanças nas atitudes de dominação dos clones, e, ainda, seu manifesto perdura pelos anos, sendo utilizado como texto sagrado cultuado pela tribo da era de 2300, influenciando seus costumes e seus valores. Da mesma forma, a atitude do advogado americano Adam Ewing, nas ilhas do Pacífico em 1849, de insurgir contra a escravidão, tem imapacto na sociedade preconceituosa de seu tempo e, ainda, nas consequências de abolição da escravatura, o que repercute nos acontecimentos futuros. Percebemos em várias outras cenas do filme como os sistemas são dinâmicos e estão conectados.

Ao considerar a aprendizagem de línguas como um processo complexo também encontramos as propriedades de dinamicidade e de conectividade, pois temos a interação de diversos elementos (aprendizes, material didáticos, recursos tecnológicos etc.). Segundo Paiva (2005) a interação não-linear desses elementos do sistema são os 


\section{Revista do SELL}

v. 5 , no. 1

ISSN: $1983-3873$

responsáveis por suas próprias mudanças. Esse sistema está sempre em movimento, ou seja, é dinâmico.

Como apontado, sistemas dinâmicos são aqueles propensos a mudar com o tempo. Larsen-Freeman e Cameron (2008) destacam que não só os elementos e agentes mudam com o tempo, mas também o modo por meio do qual os elementos interagem uns com os outros. Segundo as autoras, as alterações podem ser discretas, quando ocorrem em etapas ou estágios, ou contínuas, quando nunca cessam. Mudanças são a base da complexidade e agentes e elementos se reorganizam à medida que ganham experiência (LARSEN-FREEMAN; CAMERON, 2012).

A propriedade de dinamicidade do sistema complexo se destaca no excerto da autobiografia de 'Não's:

\section{Excerto \# 1 - Não}

Comecei por ser necessário dominar um mínimo de inglês para jogar vídeo game, depois haviam disciplinas obrigatórias na escola. Para googlar é melhor pesquisar em inglês pois há mais sites neste idioma. $O$ curso do isf gerou um desafio pois eu só sabia LER inglês, nunca me preocupei em escrever, falar e ouvir e o contato com os alunos do intercâmbio dos EUA me fez me interessar mais no ato de falar/ouvir o idioma inglês (N. Narrativa 62, Uberlândia, 2015. Estudante do programa Idiomas sem Fronteiras - Inglês).

A relação entre aprendizagem de idiomas e uso de recursos tecnológicos é evidente no excerto \# 1. Dentre os gatilhos para que 'Não' iniciasse seus estudos em língua inglesa, se destaca a necessidade de utilizar recursos tecnológicos - jogar videogame e Googlar para encontrar dados em inglês. Em um sistema complexo seus elementos interagem dinamicamente e adaptam-se uns aos outros e ao ambiente, isto significa que 'Não' (agente do sistema) ao buscar aprimorar seus conhecimentos em língua inglesa (elemento do sistema) tinha como objetivo se adaptar a um contexto (enquanto jogador). A dinamicidade do sistema faz com que este seja sensível a feedback e procure se acomodar e otimizar os benefícios que garantem a fluidez de seu funcionamento. As interações e adaptações feitas por 'Não' para alcançar seus objetivos

3Rosa (2015) identificou os participantes de sua pesquisa de dissertação por pseudônimos escolhidos pelo participantes ao responder o questionário. A identificação das narrativas por apelidos visava garantir 0 anonimato e para que, posteriormente, o próprio aprendiz se reconhecesse no texto por meio do código criado por ele mesmo. Deste modo, os excertos apresentados durante a análise serão identificados por estes codinomes. 


\section{Revista do SELL}

v. 5 , no. 1

ISSN: 1983-3873

fez com que ele criasse um novo padrão de comportamento e se tornasse um aprendiz de inglês. Suas atitudes para aprendizagem, ainda, se mostram conectadas e imbricadas umas nas outras.

\section{NÃO LINEARIDADE E EMERGÊNCIA A PARTIR DE “BABEL”}

A não linearidade como característica do sistema adaptativo complexo será discutida com base no filme Babel (IÑARRITU, 2006) que envolve, em sua narrativa, três episódios em que as ações se desenrolam simultaneamente em quatro países Marrocos, Japão, Estados Unidos e México. A primeira cena acontece no deserto de Marrocos, onde ocorre a venda de uma arma a um senhor criador de ovelhas e seus dois filhos. Esta arma serve como ponto de ligação para as cenas de todo o filme, pois quando dois jovens, filhos do criador de ovelhas, brincam com a arma nas montanhas, testando a distância percorrida pelo disparo da bala, e miram em um ônibus que transportava pessoas de diversas nacionalidades, a bala atinge uma mulher americana.

A segunda cena apresentada no filme é a Califórnia, onde estão os filhos da americana baleada, sob os cuidados da babá, que espera a volta dos patrões para ir ao casamento do filho no México, numa cidade fronteiriça com os Estados Unidos. O incidente faz com que os americanos (a mulher baleada e seu marido) adiem seu retorno para a Califórnia. Numa atitude um tanto quanto desesperada, a babá decide levar as crianças ao casamento, conduzida por seu sobrinho. No retorno para a Califórnia, ao passar pela fronteira e fiscalização da imigração, o sobrinho embriagado foge da polícia por não aguentar as provocações dos guardas e deixa a tia e as crianças no meio do deserto para uma série de encontros e desencontros.

A terceira cena é decorrente a uma caçada pelos responsáveis do tiro que atingiu a americana. Na busca pelo proprietário descobre-se que o pai de uma jovem japonesa doou a arma para seu guia, quando foi como turista ao Marrocos, ao seu guia. Este vende a arma ao pai dos meninos.

Babel (IÑÁRRITU, 2006) ilustra que os sistemas complexos existem permeados por mudanças contínuas, ou seja, pelo dinamismo. Esta característica fica evidente pelo enredo que rompe com a ideia de causa e efeito tradicional e exibe relações entre seus elementos e componentes, a princípio, imperceptíveis. O dinamismo significa que as condições iniciais, assim como o feedback, afetam sistema. O tiro disparado pelos garotos marroquinos atinge, não intencionalmente, a americana; ao perceberem o que fizeram os 


\title{
Revista do SELL
}

v. 5 , no. 1

ISSN: $1983-3873$

garotos fogem assustados. Essas ocorrências contribuem para que o sistema altere seu curso; cada mudança influencia a trajetória do enredo.

Adicionalmente, um exemplo da não linearidade da trama ocorre no momento de interação do casal americano com a babá responsável por seus filhos. Ao solicitarem que a babá cuidem de seus filhos mais tempo do que o previsto (causa) a babá leva as crianças para o México, resultando em problemas com a imigração (impacto). Os problemas colocam as crianças em risco (causa), afligindo os pais (impacto).

A complexidade emerge da não linearidade das relações e interconexões dos componentes do sistema dinâmico. O caos trata-se do período em que "os sistemas complexos não lineares entram em completa aleatoriedade de forma irregular e imprevisível" (LARSEN-FREEMAN, 1997, p. 143). Isso não quer dizer que os sistemas estejam constantemente em estado de caos e que a imprevisibilidade seja constante, e sim que há momentos da trajetória dos sistemas que são caóticos. Ao serem imprevisíveis, os sistemas podem fazer com que algo considerado pequeno ou insignificante provoque grandes resultados. De igual modo, o oposto pode acontecer, grandes causas podem produzir implicações insignificantes. A imprevisibilidade dos sistemas complexos se deve à sua sensibilidade às condições iniciais, o que implica que a evolução do sistema pode ser alterada por pequenas perturbações (LARSENFREEMAN; CAMERON, 2012).

As palavras de 'Lucas 3' demonstra alterações resultantes de pequenas perturbações:

\begin{abstract}
Excerto \# 2 - Lucas 3
O ISF com aulas presenciais é excelente! Eu aprendi muito com os cursos que eu fiz. Em todas as aulas que tive, as professoras souberam conduzir muito bem as aulas. Creio que em uma classe, o recurso tecnológico básico, seria o projetor, mas na maioria das aulas na UFU este item básico não funciona corretamente. Então em vista disto, o ensino sem a dependência de tecnologia seja o caminho (Grifos nossos) (L. 3. Narrativa 45, Uberlândia, 2015. Estudante do programa Idiomas sem Fronteiras - Inglês).
\end{abstract}

A partir do excerto \# 2 é possível perceber que 'Lucas 3' considera que a tecnologia está implícita no ambiente de sala de aula. Prova disto é que ele considera o projetor como um recurso básico para a condução da aula. Esta sua percepção sobre a normalização da tecnologia para a aprendizagem é modificada pelas perturbações do sistema. O fato de o recurso não funcionar na maioria das aulas desequilibra o sistema e faz com que o aprendiz reflita sobre novos caminhos de aprendizagem, sem a "dependência da tecnologia". Porque o sistema não possui um equilíbrio, isso resulta na 


\section{Revista do SELL}

v. 5 , no. 1

ISSN: $1983-3873$

emergência de fenômenos inesperados, como a interrupção da aula por problemas técnicos. Não é possível prever o que irá acontecer ao sistema ao ser considerado cada elemento e agente isoladamente, pois este opera por meio de uma relação conjunta e interdependente.

\section{IMPREVISIBILIDADE E SENSIBILIDADE ÀS CONDIÇÕES INICIAIS A PARTIR DE " 0 CURIOSO CASO DE BENJAMIN BUTTON"}

Imprevisibilidade e sensibilidade às condições iniciais estão presentes no filme 0 curioso caso de Benjamin Button (FINCHER, 2008). O filme é uma adaptação do conto escrito por Francis Scott Fitzgerald (1896-1940) e apresenta a história de um homem que nasce com a aparência de um idoso e, ao longo da vida, rejuvenesce gradativamente. Benjamin Button nasce velho, à beira da morte e muito doente. Com a perda da mãe ainda no parto e a rejeição súbita do pai, foi deixado na porta de um abrigo para idosos em Nova Orleans, onde é criado e amado por Queenie, que o vê como um milagre. Com o passar dos anos Benjamin rejuvenescia, enquanto seus amigos idosos logo morriam.

A história se desenvolve partindo do romance de Benjamin com Daisy, moça de sua idade por quem se apaixona, mas precisa esperar que suas idades aparentes se aproximem para que os dois possam finalmente se envolver. $\mathrm{O}$ casal se aproxima e se distancia em diversos momentos da trama. Um desses momentos chama a atenção por exemplificar a imprevisibilidade e a sensibilidade às condições iniciais características dos sistemas adaptativos complexos. A cena citada trata-se do atropelamento de Daisy, a qual resulta em sequelas que a impossibilitam profissionalmente. Benjamin assume o papel de narrador e descreve uma série de pequenos atos e coincidências que contribuem para provocar um acidente de carro que altera por completo o rumo da dançarina. A cena é transcrita a seguir:

Às vezes, nós estamos numa rota de colisão e nem sequer sabemos. Seja sem querer ou de propósito, não há nada que possamos fazer. Uma mulher em Paris estava indo fazer compras, mas tinha esquecido o casaco e voltou para pegá-lo. Quando ela voltou, o telefone tocou. Ela parou para atender e falou por alguns minutos. Enquanto ela falava, Daisy estava ensaiando para um espetáculo no teatro da Ópera de Paris. Enquanto ela ensaiava, a mulher, que havia desligado tinha saído para chamar um táxi. Um passageiro tinha saltado e o motorista parou para tomar um café. Enquanto isso, Daisy ainda estava ensaiando. E o motorista, que havia deixado o passageiro e parado para um café, pegou a moça que tinha perdido o táxi anterior. $O$ táxi parou para um homem atravessar a rua. Ele tinha saído cinco minutos mais tarde que de costume, pois não havia ligado o despertador. Enquanto o homem, atrasado, atravessava a rua, Daisy tinha 


\section{Revista do SELL}

v. 5 , no. 1

ISSN: $1983-3873$

acabado de ensaiar e estava tomando banho. E enquanto Daisy tomava banho, o táxi esperava a mulher pegar na loja um pacote que não estava embrulhado porque a moça encarregada havia brigado com o namorado na noite anterior e havia esquecido. Quando a mulher, com o pacote embrulhado, voltou para o táxi, um caminhão o havia bloqueado. Enquanto isso, Daisy estava se vestindo. $O$ caminhão foi embora e o táxi prosseguiu enquanto Daisy, a última a se vestir, esperava uma amiga que tinha arrebentado o cadarço. Enquanto o táxi esperava o sinal abrir, Daisy e sua amiga saíram pelos fundos do teatro. E se só uma coisa tivesse acontecido de forma diferente: o cadarço não tivesse arrebentado ou o caminhão tivesse saído um pouco antes ou o pacote já estivesse pronto, pois a garota não tinha brigado com o namorado, ou o homem tivesse levantado cinco minutos mais cedo ou o taxista não tivesse parado para tomar café ou a mulher tivesse se lembrado do casaco e tomado o táxi anterior, Daisy e a amiga teriam atravessado a rua e o táxi teria passado por elas. Mas, sendo a vida uma série de vidas cruzadas e incidentes fora do controle de qualquer um, aquele táxi não passou e o motorista teve uma distração momentânea fazendo com que o táxi atropelasse Daisy e esmagasse sua perna (FINCHER, 2008).).

Sistemas Adaptativos Complexos se caracterizam por sua imprevisibilidade e sensibilidade às condições iniciais. Cada pensamento momentâneo ou ação representa um "ponto de impacto" no sistema, o qual pode provocar grandes resultados. Há um processo complexo (no qual tudo está conectado) e caracterizado pela (aparente) imprevisibilidade de comportamento, bem como pela sensibilidade a pequenas variações nas condições iniciais de um sistema dinâmico.

A imprevisibilidade do sistema faz com que algo considerado pequeno ou insignificante modifique seu rumo e padrões. No filme é descrito que "uma mulher em Paris estava indo fazer compras, mas tinha esquecido o casaco e voltou para pegá-lo" (FINCHER, 2008). O fato de a mulher esquecer o casaco altera as condições iniciais do sistema, o qual é imprevisível e faz emergir fenômenos inesperados.

Nenhum sistema é isento de mudança, pois muitos dos elementos que interagem apresenta, sua própria medida de instabilidade e imprevisibilidade. Assim, pequenas alterações - a mulher esquecer seu casaco - podem ter efeitos significativos no sistema e ocasionar grandes implicações em seu comportamento futuro - atropelamento de Daisy. O mesmo pode ser observado no processo de aprendizagem de inglês, que é narrado pelo estudande de pseudônimo Lucas. O excerto \# 3 exemplifica as propriedades de sensibilidade às condições iniciais e de imprevisibilidade:

\section{Excerto \# 3 - Lucas}

Comecei a me interessar pelo idioma quando ainda era jovem, com os meus 17 a 18 anos. Ao ver alguns filmes legendados, queria entender, sem precisar ler as legendas, o que os personagens diziam. Então comecei a ler os verbos em um dicionário de inglês simples. Poco depois comecei a jogar um jogo de nível global, onde os jogadores podiam se comunicar. Através do chat do jogo aprendi 


\section{Revista do SELL}

v. 5 , no. 1

ISSN: $1983-3873$

muitas palavras novas, no entanto sem nenhuma regra de gramatica. Foi apenas com 21 anos que frequentei aulas de inglês em uma escola específica para ensino. Porem fiz apenas 6 meses de aulas. Sempre gostei de inglês e continuei buscando aprender através de canções e da ajuda da internet. Após ingressar na UFU, fiz a inscrição para participar do MEO. Não me adaptei ao programa devido a não ter um horário fixo para estudar por dia, cada dia tinha que entrar em um horário, pois minhas aulas variam de matutinas até noturnas. Com a divulgação das aulas presencias do ISF acabei deixando o MEO de lado. Estou gostando muito das aulas do ISF. A turma é pequena e bem entrosada. Usamos o whatsapp e temos também um grupo no facebookpara conversar, tirar dúvidas, postar alguma coisa relacionada ao ISF. Estou bem contente com o que tenho aprendido no programa (grifos nossos)(L. Narrativa 53, Uberlândia, 2015. Estudante do programa Idiomas sem Fronteiras - Inglês).

O excerto \# 3 expõe diversas mudanças no contexto de aprendizagem de Lucas a partir das condições iniciais, quando ele se mostrou curioso em compreender filmes em inglês. Apesar destas mudanças, uma constante é perceptível: todo o processo de aprendizagem se relaciona com a aquisição de uma língua adicional incluindo recursos tecnológicos. 'Lucas' utilizou como ferramenta de aprendizagem canções, filmes, jogos, whatsapp, Facebook. Deste modo, o uso frequente de recursos tecnológicos pode significar que os resultados alcançados sejam satisfatórios e, portanto, contínuos. Esta continuidade nos permite vislumbrar certos padrões de comportamento, porém estes não são estáticos e sua dinamicidade é frequentemente remodelada gerando resultados diferentes. Como exemplo, se a turma precisa postar uma atividade no Facebook e isto não é possível por problemas técnicos, o resultado será diferente do esperado. Pequenas perturbações no sistema podem fazer com que eventos imprevisíveis gere resultados positivos ou negativos.

\section{AUTO-ORGANIZAÇÃO E SENSIBILIDADE AO FEEDBACK A PARTIR DE "CORRA LOLA CORRA"}

Os sistemas complexos, ao serem considerados imprevisíveis, possuem uma sensibilidade não apenas às condições iniciais, mas também ao feedback, o que implica que a evolução do sistema pode ser alterada por pequenas perturbações. O filme "Corra, Lola, corra" (TYKWER, 1998) ilustra como pequenas alterações no que poderia ser a mesma trajetória podem gerar efeitos diversos.

Em resumo, "Corra, Lola, corra" (TYKWER, 1998) demonstra a tentativa de Lola (personagem principal) de salvar a vida do namorado, Manni. O enredo se inicia quando Manni telefona para Lola relatando que perdeu o dinheiro de seu chefe mafioso e que isso causaria sua morte, caso não encontrassem uma forma de repor o valor perdido. (Essas 


\section{Revista do SELL}

v. 5 , no. 1

ISSN: 1983-3873

são as condições iniciais, que não se alteram no decorrer do filme.) Para Manni, a solução era assaltar uma loja, o que Lola foi contra, afirmando que poderia solucionar o problema de outra forma. Manni oferece a Lola o prazo de vinte minutos antes de agir. Na tentativa de conseguir o dinheiro, Lola procura seu pai no banco em que ele trabalha. Para chegar ao local Lola corre desesperadamente pelas ruas da cidade. O pai da personagem se recusa a ajudá-la, então ela reinicia sua corrida para se encontrar com o namorado e quando o encontra ele já está realizando o assalto. Ela decide ajudá-lo e acaba sendo baleada pela polícia. O filme continua com o mesmo enredo e dois novos possíveis finais para o contexto são apresentados, porém pequenas mudanças no cenário narrado são demonstradas partindo da possibilidade de que Lola pode retornar ao momento em que desliga o telefone após ser informada por Manni que o dinheiro foi perdido. Desta vez, ela demora um pouco mais para descer as escadas quando passa pelo personagem que segura o cachorro. Quando ela chega no banco e conversa com seu pai, o cenário também se modifica em função do pequeno atraso em relação à primeira tentativa e, como resultado, Lola decide assaltar o banco de seu pai. Chegando ao local, Manni é atropelado e morto por um carro que passa por Lola na primeira versão segundos antes de ela chegar ao banco. Com o fracasso das duas primeiras tentativas de salvar o namorado, Lola volta no tempo novamente, retornando ao momento em que desliga o telefone. Sem saber o que fazer e buscando uma nova tentativa de conseguir o dinheiro, a personagem decide fazer apostas em um cassino, onde ela consegue ganhar 0 dinheiro. Com o dinheiro em mãos ela começa a correr para se encontrar com Manni. $\mathrm{O}$ dinheiro perdido no início do filme foi encontrado por um mendigo. Enquanto Lola jogava no cassino, Manni encontra esse mendigo e consegue recuperar seu dinheiro. Após recuperá-lo, ele vai ao encontro de seu chefe para devolver o montante e é neste momento que Lola se reencontra com Manni.

Em "Corra, Lola, corra" notamos que pequenas mudanças no seu caminho para chegar ao local do encontro propiciam que o sistema se auto-organize provocando efeitos ou resultados diversos. Exemplificamos com um detalhe mostrado no filme: quando Lola inicia sua corrida para chegar até seu pai ela desce as escadas de seu prédio e passa por uma pessoa segurando um cachorro. Seu tempo de descida das escadas se modifica ao cruzar com o cachorro o que a atrasa e impossibilita seu encontro com seu pai, gerando uma nova trajetória para o enredo. Considerando a trama sob a ótica da complexidade é 


\section{Revista do SELL}

v. 5 , no. 1

ISSN: 1983-3873

possível perceber que alterações levam a caminhos diferentes e resultam em um estado final distinto.

Considerando as propriedades dos sistemas complexos, temos elementos ou agentes que interagem entre si e se auto-organizam constantemente. Segundo Morin (2006, p. 65) "cada sistema cria suas próprias determinações e suas próprias finalidades", assim uma das características do sistema adaptativo complexo é a possibilidade de autoorganização. Ao se auto-organizar o sistema adapta seu comportamento.

Franco (2013, p. 39) afirma que "o sistema comporta trocas materiais/energéticas com o exterior, seus elementos se reorganizam entre si a partir da desordem". O autor afirma ainda que "a auto-organização é possível devido ao fato de os sistemas complexos serem altamente sensíveis ao feedback" (FRANCO, 2013, p. 40). A imprevisibilidade dos sistemas faz com que eles se auto-organizem na medida em que recebem feedback e energias e matérias externas, considerando que ossistemas são abertos. Todas estas características permitem que o sistema se modifique e evolua para alcançar seu objetivo (LARSEN-FREEMAN; CAMERON, 2012).

No excerto \# 4 observamos a propriedade de auto-organização também no processo de aprendizagem de inglês:

\footnotetext{
Excerto \# 4 -<Arantes>

De fato a utilização da tecnologia associado, ao ISF facilita algum entendimento não fixado durante a aula seja ela presencial ou online (consulta a vídeos e blogs disponíveis na internet). Além desta ferramenta, ser objeto de complemento dos professores do ISF o que auxilia nos estudos extra sala de aula (A. Narrativa 37, Uberlândia, 2015. Estudante do programa Idiomas sem Fronteiras - Inglês).
}

Ao contrário do excerto \#1 em que a tecnologia é um 'gatilho', 'Arantes' considera que recursos tecnológicos são uma ferramenta facilitadora da aprendizagem. De acordo com o excerto \# 4 a tecnologia ajuda a reorganizar e estabilizar o sistema, deste modo, apesar de surgirem dúvidas no processo de aprendizagem, 'Arantes' busca na tecnologia meios de contornar obstáculos e se auto-organizar. A aula presencial ou on-line, tomada como condição inicial, não é a única fonte de influência para o percurso de aprendizagem; o acesso a tecnologias digitais na trajetória do estudante constitui-se feedback e permite que o sistema se auto-organize. 


\section{Revista do SELL}

v. 5 , no. 1

ISSN: $1983-3873$

\section{ABERTURA E CAOS A PARTIR DE "EFEITO BORBOLETA"}

A abertura do sistema permite que novas matérias e energias fluam para dentro e para fora desse sistema; ao passo que evolui, a absorção de energia do ambiente aumenta sua ordem e sua complexidade. Em oposição ao sistema fechado, cujo estado final é inequivocamente determinado pelas condições iniciais, o sistema aberto mantémse em contínuo fluxo de entrada e de saída. Ele se conserva mediante a construção e a decomposição de componentes, nunca estando, enquanto vivo, em um estado estático (SOUZA, 2011).

O filme Efeito Borboleta (BRESS; GRUBER, 2004) tem um enredo que gira em torno de Evan Treborn. Evan cresce em uma cidadezinha com sua mãe solteira e seus amigos. Ele sofre de falhas de memória e mostra-se confuso. Desde os sete anos de idade ele escrevia em um diário esses momentos de blackout para que se lembrasse do que aconteceu. Ele descobre que pode viajar no tempo e que ele é capaz de modificar partes do seu passado. Suas ações e aquelas que são possibilitadas aos que interagem com ele nos momentos de blackout mudam o contexto de cada situação futura quando ele acorda. As consequências de suas escolhas perpetuam em sua vida presente: os futuros alternativos que ele vive variam entre estudante universitário, para prisioneiro, para amputado. Seus esforços de voltar no tempo são movidos por seus desejos de desfazer os eventos mais desagradáveis de sua infância, inclusive de salvar a garota por quem ele é apaixonado. Ao continuar suas viagens no tempo ele percebe que mesmo com boas intenções, suas ações têm resultados imprevisíveis. Ao final, ele viaja de volta ao tempo pela última vez e garante que a garota de seus sonhos nunca mais se aproxime dele, assustando-a. Consequentemente, ele garante que ela fique salva.

Larsen-Freeman e Cameron (2012, p. 29) afirmam que a "complexidade de um sistema complexo surge a partir de componentes e subsistemas interdependentes, que interagem uns com os outros de formas diferentes". Ao voltar ao passado e modificar as condições iniciais, Evan influencia na relação dos componentes e subsistemas e faz com que ocorra uma quebra da estabilidade do sistema, ou seja, o espaço em que a narrativa se constrói é modificado e desencadeia uma mudança nos feedbacks recebidos pelo sistema.

No filme, ao voltar no tempo, são criadas realidade múltiplas. Isto significa que novos componentes e elementos são criados e modificados. As mudanças acontecem em 


\title{
Revista do SELL
}

v. 5 , no. 1

ISSN: 1983-3873

função da troca de insumo ou energia com o ambiente. Esta troca em função da abertura do sistema adaptativo complexo faz com que ocorram adaptações ao novo ambiente, o qual busca se otimizar e auto-organizar.

A criação de realidades múltiplas e interdependentes se baseiam nos feedbacks recebidos pelo sistema. A cada 'viagem' ao passado feita por Evan, uma nova realidade se instaura desestabilizando o sistema, o que permite que a troca de insumo ou energia com o ambiente promova adaptações. As mudanças que acontecem, natural e automaticamente, nos sistemas podem ser definidas pelo processo de auto-organização. Os elementos reorganizam-se entre si e com suas interfaces, visando alcançar seus objetivos.

No sistema complexo da aprendizagem de inglês estão presentes interações de diversos elementos, e, considerando que o sistema é aberto, ele está sujeito a um contínuo fluxo e influxo de experiências, como no filme 'Efeito Borboleta".

O excerto \# 5 exemplifica a abertura do sistema:

\begin{abstract}
Excerto \# 5 - Unnamed
O uso de tecnologias no ensino de línguas é essencial, pois torna possível o contato com práticas e exemplos de melhor entendimento dos alunos, além de criar um contato maior com todos eles. Utilizo tecnologia diariamente, praticamente em todas as atividades realizadas. Utilizo muito a internet para aprender inglês, principalmente através de seriados e filmes (U. Narrativa 33, Uberlândia, 2014. Estudante do programa Idiomas sem Fronteiras - Inglês).
\end{abstract}

Os sistemas adaptativos complexos são abertos, isto é, troca insumo ou energia com o ambiente e são suscetíveis às mudanças resultantes de feedback. Isto significa que, de acordo com o excerto, o uso de recursos tecnológicos é considerado por 'Unnamed' como enriquecedor do processo de aprendizagem. Deste modo, novos fatores são inseridos no sistema e influenciam seu comportamento. A abertura do sistema faz com que ocorram adaptações ao novo ambiente e aprenda, por meio de sua própria experiência a se auto-organizar e a buscar os melhores resultados (BRAGA, 2007) .

\section{ADAPTABILIDADE E BIFURCAÇÃO A PARTIR DE "TEORIA DO CAOS"}




\section{Revista do SELL}

v. 5 , no. 1

ISSN: 1983-3873

A adaptabilidade característica dos sistemas adaptativos complexos é demonstrada no filme Teoria do Caos (SIEGA, 2007). O filme narra a hstória de Frank, um homem que planeja cada segundo do seu tempo, organizando suas atividades em fichas no formato de listas. Em uma manhã ele teve problemas com sua esposa e se atrasa para iniciar sua atividades rotineiras. A partir do momento em que sai de casa uma série de eventos inesperados começam a acontecer. No caminho para o trabalho ele bate em outro carro, no qual tinha uma mulher em trabalho de parto. Frank socorre a mulher e o hospital o confunde com o pai da criança. O hospital entra em contato com Susam, pensando ser ela a mãe da criança. O engano é entendido pela esposa como uma traição de Frank. Ele é expulso de casa até que prove não ser o pai do recém nascido. A fim de solucionar o problema, um exame de paternidade é feito. Ao fazer o exame, ele descobre que é estéril e que não poderia ser o pai biológico de sua filha de sete anos. Diante das adversidades que surgiram, Frank deixa de lado o controle e método. Ele começa a beber e, como símbolo de que não tem controle sob sua própria vida, apenas escreve todas as opções de ações em fichas e ao acaso pega uma.

A breve descrição do contexto e personagens de Teoria do Caos (SIEGA, 2007) demonstra que a vida é um sistema complexo cuja evolução acontece mediante troca de energia com o ambiente, por meio de mecanismos não lineares, pressionando o sistema para além dos limites de estabilidade.

Deste modo, os parâmetros mudam, em um sistema dinâmico, assim como se modificam os pontos de equilíbrio. O estudo das mudanças da estabilidade do sistema, que pode ser provocada pelos atratores, e do número de pontos de equilíbrio em problemas não-lineares quando os parâmetros do sistema são variados, é o objeto da Teoria da Bifurcação (MOON, 2004). Prigogine (2002) sublinha o reaparecimento do paradoxo do tempo; ou seja, a observação de que se faz necessário atentar para o fator diacrônico nas investigações científicas. O que levou a esse entendimento foi, essencialmente, a descoberta das estruturas de não-equilíbrio e, consequentemente, nãolineares. O que se nota nessas estruturas são bifurcações na evolução de um sistema; ou seja, há uma mudança de fase, quando o comportamento muda repentinamente para um novo modo, uma fase radicalmente diferente da anterior.

O filme demonstra que a realidade não pode ser reduzida a leis universais. Nas palavras de Morin (2006), "pensar a complexidade é o maior desafio do pensamento 


\section{Revista do SELL}

v. 5 , no. 1

ISSN: 1983-3873

contemporâneo, que necessita de uma reforma no nosso modo de pensar." (MORIN, 2006, p. 199). No sistema adaptativo complexo os componentes e elementos estão em constante mudança, não sendo possível prever seu comportamento.

Com as mudanças e imprevisibilidades, os elementos do sistema se autoorganizam à medida que ele ganha experiência visando se aprimorar (LARSENFREEMAN; CAMERON, 2012). O excerto \#6 demontra esta adaptação. 'Gugu_lindão' resume em poucas palavras sua trajetória de aprendizagem de inglês:

\section{Excerto \# 6 - Gugu_lindão>}

Resumindo: ensino médio me ensinaram porcamente, e depois, na faculdade tive que correr atrás e escutar sozinho, com livros e internet.Agora inglês sem fronteiras e em casa sozinho com auxílio de vídeos, internet e livros e apostilas online (G. L. Narrativa 45, Uberlândia, 2015. Estudante do programa Idiomas sem Fronteiras - Inglês).

Assim como no excerto de 'Arantes', 'Gugu_lindão' utiliza recursos tecnológicos para complementar seus estudos. A busca por estes recursos se deve ao fato de ele se sentir frustrado com os cursos de idiomas anteriores ao ISF-Inglês, logo foi necessário sua adaptação para alcançar seus objetivos. É possível perceber no excerto de 'Gugu_lindão', que sua busca autônoma teve resultados mais positivos que os das aulas do ensino médio. Esse mesmo contexto poderia ter um resultado diferente para outro aprendiz e o estudo autônomo poderia não render e ser negativo. O excerto demonstra a adaptabilidade do sistema, isto significa que é possível perceber a interação dos elementos do sistema ao longo do tempo e, esta interação, não alcança resultados previsíveis ou proporcionais.

\section{CONSIDERAÇÕES FINAIS}

Em geral, foi possível observar que as propriedades dos sistemas complexos dinamicidade, conectividade, não-linearidade, emergência, imprevisibilidade, sensibilidade às condições iniciais, auto-organização, sensibilidade à feedback, bifurcação, adaptabilidade, caos e abertura - são retratadas nas tramas das produções cinematográficas. Acreditamos que os filmes possam ser úteis para aqueles que se 


\section{Revista do SELL}

v. 5 , no. 1

ISSN: 1983-3873

interessam pelo Paradigma da Complexidade por oportunizarem que seus telespectadores observem tais propriedades em contextos ricos pela integração midiática.

Em termos de contexto de processo de aprendizagem, os dados evidenciaram que o percurso dos estudantes de inglês do Programa Idiomas sem Fronteiras - inglês também se mostra complexo e que podemos perceber a presença das propriedades do paradigma da complexidade analisadas. As trajetórias narradas pelos estudantes expressam que tais propriedades estão imbricadas em seus contextos de aprendizagem, recorrentemente marcados pelos recursos tecnológicos.

Nessa linha, destacamos a importância de atentarmos para a complexidade do mundo fenomênico em que vivemos. Defendemos que olhar pelas lentes complexas sob uma perpectiva não reducionista pode nos ajudar a compreender melhor os fenômenos. Relembramos que, segundo Bertalanffy (1975, p. 130), reducionismo é o "princípio segundo o qual a biologia, as ciências sociais e do comportamento deviam ser tratadas de acordo com o paradigma da física e finalmente reduzidas a conceitos de entidades do nível físico". Isso quer dizer que havia a necessidade de que qualquer conclusão tecida após uma investigação de qualquer área do conhecimento fosse reformulada, em termos de cálculos e estatísticas, para que fossem validadas canonicamente. Em uma perspectiva reducionista: 1) as pesquisas deveriam ser reduzidas a buscar situações de causa e efeito, de preferência que pudessem ser explicadas estatisticamente; e 2) as disciplinas eram reduzidas ao seu campo de atuação, sem que dialogassem com outras disciplinas em situações inter e pluridisciplinares.

O que defendemos para a Linguística Aplicada é o oposto do Reducionismo. A riqueza dos conceitos provenientes do Paradigma da Complexidade nos permitiu compreender as produções cinematográficas e as narrativas dos estudantes valorizando as partes e o todo, qualitativamente e não estatisticamente. Além disso, permitir que a arte do cinema dialogasse com o processo de aprendizagem de inglês influenciado pelas tecnologias digitais propiciou que percorressemos um caminho interdisciplinar, que esperamos ser agradável aos nossos leitores, assim como foi para cada uma de nós.

\section{REFERÊNCIAS}

BABEL. Direção: Alejandro González Iñárritu. Estados Unidos / França / México: nonymousContent / Central Films / Media Rights Capital / Paramount Pictures / Paramount Vantage / ZetaFilm, 2006. 1 filme (142 min. ), son.. color. 


\section{Revista do SELL \\ v. 5 , no. 1 \\ ISSN: $1983-3873$}

BENSON, P.; NUNAN, D. Learners' stories: difference and diversity in language learning.Nova York: Cambridge University Press, 2005.

BERTALANFFY, L. Teoria geral dos sistemas. 2. ed. Tradução de Francisco M. Guimarães. Petrópolis: Vozes, 1975.

BRAGA, J. C. F. Comunidades autônomas de aprendizagem on-line na perspectiva da complexidade. 2007. Tese (Doutorado) - FALE, UFMG, Belo Horizonte, 2007. Disponível em: <https://www.google.com.br/url?

$\mathrm{sa}=\mathrm{t} \& \mathrm{rct}=\mathrm{j} \& \mathrm{q}=\&$ \&esrc=s\&source=web\&cd=1\&ved=0CB8QFjAA\&url=http$\% 3 \mathrm{~A} \% 2 \mathrm{~F}$

\%2Fwww.bibliotecadigital.ufmg.br\%2Fdspace\%2Fbitstream\%2F1843\%2FALDR-

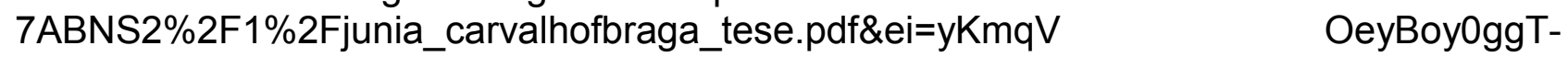
mID4Dw\&usg=AFQjCNḠIhjCemBv0fxOF̄D_RWYccOc2V_0A\&sig2=9MMcjvg5eYEy3zdU wswTMw>. Acesso em: 26 set. 2014.

CLOUD ATLAS. Direção: Andy Wachowski, Lana Wachowski, Tom Tykwer. Alemanha: Imagem Filmes. 2013

. 1 filme (172 minutos), son..color.

CORRA Lola Corra. Direção: Tom Tykwer. Alemanha: X-Filme Creative Pool / WestdeutscherRundfunk/ German Independents / Arte / Bavaria Film, 1998. 1filme (81 minutos), son. color.

DAVIS, B.; SUMARA, D. Complexity and education: inquiries into learning, teaching and research. New Jersey; London: Lawrence Erlbaum Associates, 2006. 202 p.

EFEITO Borboleta (The Butterfly Effect). Direção: Eric Bress_/ J. MackyeGruber. EUA / Canadá: Europa Filmes, 2004. 1 filme (113 minutos), son..color.

FINCH, A. Autonomy: Where are we? Where are we going? In: JALT CUE-SIG, 2002 Proceedings. p. 15-2, 2002. Disponível em: <http://www.finchpark.com/arts/autonomy/ index.htm>. Acesso em: 26 set. 2014.

FRANCO, Claudio de Paiva. Autonomia na aprendizagem de inglês: Um estudo de caso com nativos digitais sob as lentes do caos e da complexidade. 2013. 201f. Tese (Doutorado em Linguística) - Programa de Pós-Graduação em Estudos Linguísticos da Faculdade de Letras da Universidade Federal de Minas Gerais, Belo Horizonte, 2013.

KRAMSCH, C. Why is everyone so excited about complexity theory in applied linguistics?(2012). Disponível em: <http://www.atilf.fr/IMG/pdf/02.pdf>. Acesso em: 01 dez. 2014.

LARSEN-FREEMAN, D. Chaos/complexity science and second language acquisition. Applied Linguistics, v. 18, n. 2, p. 141-165, 1997.

linguistics.Oxford: Oxford University Press, 2012.

; CAMERON, L. Complex systems and applied 


\section{Revista do SELL}

v. 5 , no. 1

ISSN: $1983-3873$

LEWIN, R. Complexity: life at the edge of chaos. New York: Macmillan Publishing Company, 1992.

MOON, F. C. Chaotic vibrations: an introduction for applied scientists and engineers. New Jersey: WileyInterscience, 2004.

MORIN, E. Introdução ao pensamento complexo. Tradução de Eliane Lisboa. Porto Alegre: Sulina, 2006. 120 p.

O CURIOSO caso de Benjamin Button (The Curious Case of Benjamin Button). Direção: David Fincher. EstadosUnidos: Paramount Pictures / The Kennedy/ Marshall Company / Warner Bros. Pictures. 2009. 1 filme (166 minutos), son..color.

PAIVA, V. L. M. O. A. Modelo fractal de aquisição de línguas. In: BRUNO, F.C. (Org.) Reflexão e Prática em ensino/aprendizagem de língua estrangeira. São Paulo: Editora Clara Luz, p. 23-36, $2005 . \quad$ Disponível em: <http://www.veramenezes.com/modelo.htm>. Acesso em: 07 de out. 2013

. Autonomia e complexidade. Linguagem \& Ensino, vol. 9, n.1, p. 77-127, 2006. Disponível em: <http://rle.ucpel.tche.br/php/edicoes/v9n1/vera_paiva.pdf>. Acesso em: 30 mar. 2015.

PRIGOGINE, I. As leis do caos. Tradução de Roberto Leal Ferreira. São Paulo: Editora Unesp, 2002.

ROSA, G. C. O INVESTIMENTO E O PAPEL DAS TECNOLOGIAS DIGITAIS EM CURSOS DO IDIOMAS SEM FRONTEIRAS - INGLÊS UFU:um estudo sob a ótica da complexidade e da teoria do investimento (em andamento). 2015 - Programa de PósGraduação em Estudos Linguísticos da Faculdade de Letras da Universidade Federal de Uberlândia, Uberlândia, 2015.

SARAMAGO, José. O homem duplicado. São Paulo: Companhia das Letras, 2008.

SOUZA, V. V. S. Dinamicidade e adaptabilidade em comunidades virtuais de aprendizagem: Uma textografia à luz do paradigma da Complexidade. 2011. 256 f. Tese (Doutorado em Linguística) - Programa de Pós-Graduação em Estudos Linguísticos da Faculdade de Letras da Universidade Federal de Minas Gerais, Belo Horizonte, 2011.

TEORIA do Caos (ChaosTheory). Direção: Marcos Siega. Estados Unidos da América: Castle Rock Entertainment / Lone Star FilmGroup / Warner Bros. Pictures , 2008. 1 filme (87 minutos), son..color.

VAN LIER, L. The semiotics and ecology of language learning: perception, voice, identity and democracy. (2004). Disponível em: 


\section{Revista do SELL}

v. 5 , no. 1

ISSN: $1983-3873$

<http://www.ub.oru.se/Extern/Forskning/Forskningsmiljoer/HumUS/Utbildning_och_Demok rati/Tidskriften/2004/Nr_3/vanLier.pdf >. Acesso em: 09 jun. 2014

VETROMILLE-CASTRO, R.; DUARTE, G. B. Interação e a sala de aula de língua estrangeira em contextos digitais: uma perspectiva complexa. (2011) Disponível em: $<$ http://periodicoscientificos.ufmt.br/ojs/index.php/polifonia/article/view/26>. Acessoem: 03 dez. 2014.

WALDROP, M. Complexity: the emerging science at the edge of order and chaos. New York: Simon and Schuster, 1992. 